NASA/CR—2003-212489

\title{
Application of a Split-Fiber Probe to Velocity Measurement in the NASA Research Compressor
}

Jan Lepicovsky

QSS Group, Inc., Cleveland, Ohio 
Since its founding, NASA has been dedicated to the advancement of aeronautics and space science. The NASA Scientific and Technical Information (STI) Program Office plays a key part in helping NASA maintain this important role.

The NASA STI Program Office is operated by Langley Research Center, the Lead Center for NASA's scientific and technical information. The NASA STI Program Office provides access to the NASA STI Database, the largest collection of aeronautical and space science STI in the world. The Program Office is also NASA's institutional mechanism for disseminating the results of its research and development activities. These results are published by NASA in the NASA STI Report Series, which includes the following report types:

- $\quad$ TECHNICAL PUBLICATION. Reports of completed research or a major significant phase of research that present the results of NASA programs and include extensive data or theoretical analysis. Includes compilations of significant scientific and technical data and information deemed to be of continuing reference value. NASA's counterpart of peerreviewed formal professional papers but has less stringent limitations on manuscript length and extent of graphic presentations.

- TECHNICAL MEMORANDUM. Scientific and technical findings that are preliminary or of specialized interest, e.g., quick release reports, working papers, and bibliographies that contain minimal annotation. Does not contain extensive analysis.

- CONTRACTOR REPORT. Scientific and technical findings by NASA-sponsored contractors and grantees.
- CONFERENCE PUBLICATION. Collected papers from scientific and technical conferences, symposia, seminars, or other meetings sponsored or cosponsored by NASA.

- SPECIAL PUBLICATION. Scientific, technical, or historical information from NASA programs, projects, and missions, often concerned with subjects having substantial public interest.

- TECHNICAL TRANSLATION. Englishlanguage translations of foreign scientific and technical material pertinent to NASA's mission.

Specialized services that complement the STI Program Office's diverse offerings include creating custom thesauri, building customized databases, organizing and publishing research results ... even providing videos.

For more information about the NASA STI Program Office, see the following:

- Access the NASA STI Program Home Page at http://www.sti.nasa.gov

- E-mail your question via the Internet to help@sti.nasa.gov

- Fax your question to the NASA Access Help Desk at 301-621-0134

- Telephone the NASA Access Help Desk at 301-621-0390

- Write to:

NASA Access Help Desk

NASA Center for AeroSpace Information 7121 Standard Drive

Hanover, MD 21076 
NASA/CR-2003-212489

\section{Application of a Split-Fiber Probe to Velocity Measurement in the NASA Research Compressor}

Jan Lepicovsky

QSS Group, Inc., Cleveland, Ohio

Prepared for the

2003 Fluids Engineering Division Summer Meeting

cosponsored by the American Society of Mechanical Engineers

and the Japan Society of Mechanical Engineers

Honolulu, Hawaii, July 6-10, 2003

Prepared under Contract NAS3-00145

National Aeronautics and

Space Administration

Glenn Research Center 


\section{Acknowledgments}

The work was sponsored by the NASA Glenn Research Center under the Smart Engine Components Project managed by Mr. R.D. Corrigan as a part of the R\&T Base Propulsion and Power Program. The author would like to thank Mrs. L. Shaw, chief of the GRC Compressor Branch, for her continuous support. Support from Dr. G.E. Welch of NASA GRC and help from Ms. P.S. Prahst of AP Solutions is also gratefully acknowledged.

The Propulsion and Power Program at NASA Glenn Research Center sponsored this work.

Available from

NASA Center for Aerospace Information 7121 Standard Drive

Hanover, MD 21076
National Technical Information Service 5285 Port Royal Road Springfield, VA 22100

Available electronically at http:/ /gltrs.grc.nasa.gov 


\title{
APPLICATION OF A SPLIT-FIBER PROBE TO VELOCITY MEASUREMENT IN THE NASA RESEARCH COMPRESSOR
}

\author{
Jan Lepicovsky \\ QSS Group, Inc. \\ Cleveland, Ohio 44135
}

\section{ABSTRACT}

A split-fiber probe was used to acquire unsteady data in a research compressor. The probe has two thin films deposited on a quartz cylinder $200 \mu \mathrm{m}$ in diameter. A split-fiber probe allows simultaneous measurement of velocity magnitude and direction in a plane that is perpendicular to the sensing cylinder, because it has its circumference divided into two independent parts. Local heat transfer considerations indicated that the probe direction characteristic is linear in the range of flow incidence angles of $\pm 35 \mathrm{dg}$. Calibration tests confirmed this assumption. Of course, the velocity characteristic is nonlinear as is typical in thermal anemometry. The probe was used extensively in the NASA GRC low-speed, multistage axial compressor, and worked reliably during a test program of several months duration. The velocity and direction characteristics of the probe showed only minute changes during the entire test program. An algorithm was developed to decompose the probe signals into velocity magnitude and velocity direction. The averaged unsteady data were compared with data acquired by pneumatic probes. An overall excellent agreement between the averaged data acquired by a split-fiber probe and a pneumatic probe boosts confidence in the reliability of the unsteady content of the split-fiber probe data. To investigate the features of unsteady data, two methods were used: ensemble averaging and frequency analysis. The velocity distribution in a rotor blade passage was retrieved using the ensemble averaging method. Frequencies of excitation forces that may contribute to high cycle fatigue problems were identified by applying a digital Fourier transform to the absolute velocity data.

\section{NOMENCLATURE}
$\begin{array}{lll}b & {[m] \quad \text { blade pitch }}\end{array}$
$D_{J}[\mathrm{~m}] \quad$ calibration nozzle exit diameter
$\begin{array}{ll}d & {[m]}\end{array}$ probe fiber diameter
$E \quad[V] \quad$ signal voltage

\begin{tabular}{|c|c|c|}
\hline & & frequency \\
\hline$n$ & {$[\mathrm{~m}]$} & blade height \\
\hline$h_{d}$ & {$\left[W m^{-2} K^{-1}\right]$} & local heat transfer coefficient \\
\hline $\mathrm{k}$ & {$\left[W m^{-1} K^{-1}\right]$} & air thermal conductivity \\
\hline$K n$ & {$[1]$} & Knudsen number $\left\{K n=l_{m} / d\right\}$ \\
\hline$l_{m}$ & {$[m]$} & mean free path of molecules \\
\hline $\mathrm{Nu}$ & & Nusselt number $\left\{N u=\left(h_{d} d\right) / k\right\}$ \\
\hline $\operatorname{Re}$ & & Reynolds number $\{R e=(\rho V d) / \mu\}$ \\
\hline$t$ & {$[s]$} & time \\
\hline$V$ & {$\left[m \cdot s^{-1}\right]$} & absolute velocity \\
\hline$v_{\sigma}$ & {$\left[m \cdot s^{-1}\right]$} & root-mean-square of velocity fluctuations \\
\hline$W$ & {$\left[m \cdot s^{-1}\right]$} & relative velocity \\
\hline$y$ & {$[m]$} & tangential (pitchwise) direction \\
\hline$z$ & {$[\mathrm{~m}]$} & radial (spanwise) direction \\
\hline$\alpha$ & {$[d g]$} & absolute flow angle \\
\hline$\beta$ & {$[d g]$} & relative flow angle \\
\hline$\varepsilon$ & {$[d g]$} & probe setting angle \\
\hline$\Delta E$ & {$[V]$} & voltage difference \\
\hline$\delta E$ & {$[V]$} & deviation from zero incidence voltage \\
\hline$\Phi$ & {$[d g]$} & rotor angular distance \\
\hline$\eta$ & {$[d g]$} & probe incidence angle \\
\hline$\mu$ & {$\left[\mathrm{kg} \cdot \mathrm{m}^{-1} \cdot \mathrm{s}^{-1}\right]$} & air dynamic viscosity \\
\hline$v$ & [1] & velocity unsteadiness $\left\{v=v_{\sigma} / V\right\}$ \\
\hline$\rho$ & {$\left[\mathrm{kg} \cdot \mathrm{m}^{-3}\right]$} & air density \\
\hline$\psi$ & {$[d g]$} & angular distance \\
\hline & [1] & iteration step \\
\hline
\end{tabular}

Subscripts

$\begin{array}{ll}A & \text { amplitude } \\ A X & \text { axial } \\ T G & \text { tangential } \\ W & \text { wake } \\ 0 & \text { probe incidence angle } \eta=0 d g \\ 1 & \text { sensor \#1 } \\ 2 & \text { sensor \#2 }\end{array}$




\section{INTRODUCTION}

A low-speed axial compressor (LSAC) is used at the NASA Glenn Research Center to increase the understanding of the complex flow phenomena in axial compressors and obtain detailed data from a multistage compressor environment for use in developing and verifying models for CFD design codes. The majority of testing in compressors in general has been performed using conventional steady state pneumatic probes, even though the nature of the compressor flow is inherently unsteady. Conventional pneumatic probes are relatively inexpensive, simple to use, and deliver reliable data, which well describe the overall characteristics of tested machines. A continuous striving to improve efficiency and widen the range of stable operation of modern compressors, however, requires knowledge of unsteady flow behavior in compressors. Basically, there are two proven experimental techniques to acquire unsteady flow velocity: thermal anemometry and laser velocimetry (including particle image velocimetry). Both techniques have their place in experimental research in modern compressors. Lately, unsteady velocity measurements in the NASA LSAC are made predominantly using the thermal anemometry technique, which is the main topic of this paper.

\section{NASA LOW-SPEED MULTISTAGE AXIAL COMPRESSOR}

An overall view of the NASA research compressor facility is shown in Fig. 1. The compressor consists of a row of inlet guide vanes (IGV) followed by four identical stages, each having a rotor blade row (RBR) and a stator vane row (SVR). The compressor partial cross section and the blade / vane row layout are shown in Fig. 2. Each rotor has 39 blades, each stator consists of 52 vanes, and there are 52 vanes in the IGV row. The shroud is provided with a number of small access ports for aerodynamic probes. The compressor tip speed is $61.0 \mathrm{~m} / \mathrm{s}$, mean axial flow

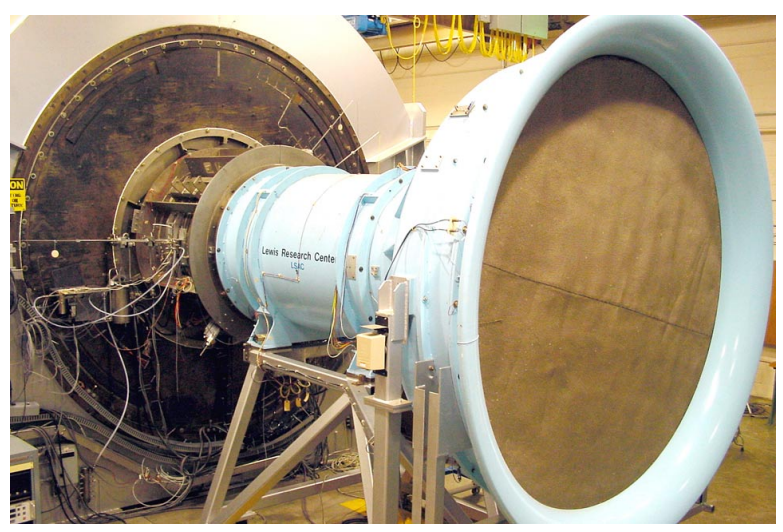

Fig. 1. NASA Glenn Research Center low speed axial compressor facility. velocity $24.4 \mathrm{~m} / \mathrm{s}$, and the overall pressure ratio is 1.042 . All data presented in this paper were acquired at this operational condition. The compressor tip radius is $610 \mathrm{~mm}$, and blade or vane height is $122 \mathrm{~mm}$. The aspect ratio (span/chord) is 1.20 for rotor rows and 1.31 for stator rows (Ref. 1).

There are two frames for of flow systems in turbomachinery components with rotating parts: a relative flow system and an absolute flow system. Variations of flow parameters in the relative flow system, as recorded by an observer sitting on a revolving rotor, differ from flow variations in the absolute flow system, recorded outside of a rotor in a nonmoving frame. The mutual relationship between these two systems is determined by the rotational velocity of the moving rotor. A rotor designer is interested in the relative flow parameters, because they indicate performance and efficiency of the component involved. However direct measurements in the relative flow system, i.e. in the revolving rotor, are extremely difficult and impractical. Probes mounted in a rotor are subjected to large centrifugal forces, probe actuators are complicated, accessibility to probes for inspection and calibration is very restricted, and signals must be transmitted from a rotating frame, which usually increases signal noise. For these reasons the vast majority of turbomachinery measurements is carried out in the absolute flow system, and the results are transformed into the relative flow system computationally.

Flow parameter variations, however, are manifested differently in the two systems; for example variations in velocity magnitude in the relative system are sensed more as variations in velocity direction in the absolute system and vice versa. The situation is illustrated in Fig. 3. The efficiency of a

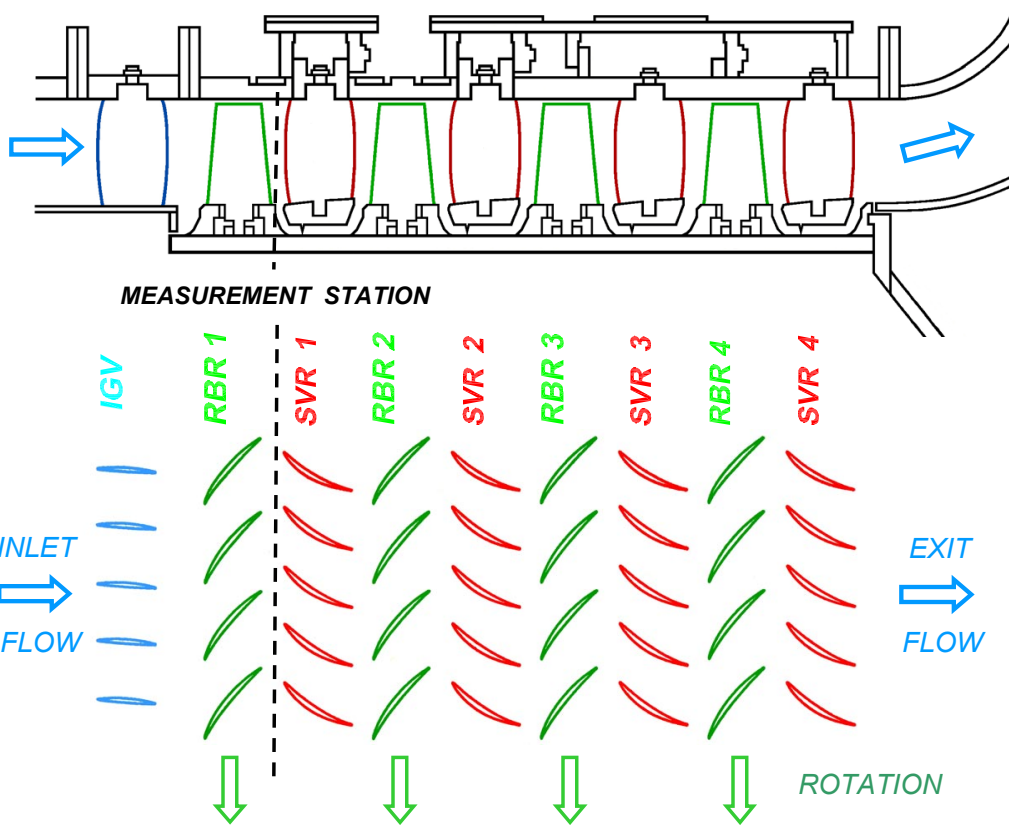

Fig. 2. Flow path and blading plan of the NASA low speed axial compressor. 


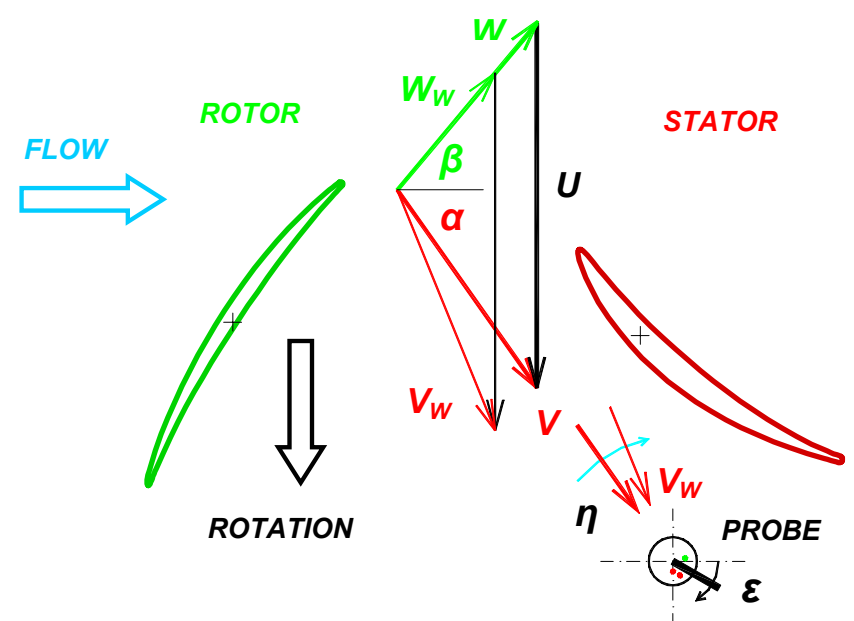

Fig. 3. Velocity triangle and probe setting.

rotor is determined from the measurement of velocity losses in the rotor wakes in relation to the velocity in the main undisturbed flow. In the relative flow system, this requires direct measurement of velocity magnitudes of the main flow velocity $W$ and the wake minimum velocity $W_{W}$ (Fig. 3). A probe in the absolute system, however, senses velocity vectors $V$ and $V_{W}$, which differ mainly in the flow direction and sometimes very little in velocity magnitude. The exact relation depends on the local circumferential velocity that determines the 'velocity triangle'. It follows that for measurements in the absolute flow frame, knowledge of the unsteady directional characteristics of probes to be used is essential, and the probes must be carefully calibrated for directional sensitivity.

\section{SPLIT-FIBER PROBE}

Hot-wire probes are excellent devices for unsteady velocity measurements, particularly in low subsonic flows. References to hot-wire anemometry are too numerous to be listed; an excellent summary of this topic is given in Ref. 2. A single hot-wire probe, however, is insensitive to velocity direction in the plane perpendicular to the sensing wire for an angle range up to $\pm 90 d g$ (as long as there is no interference with the probe prongs). A hot-wire signal is a measure of a
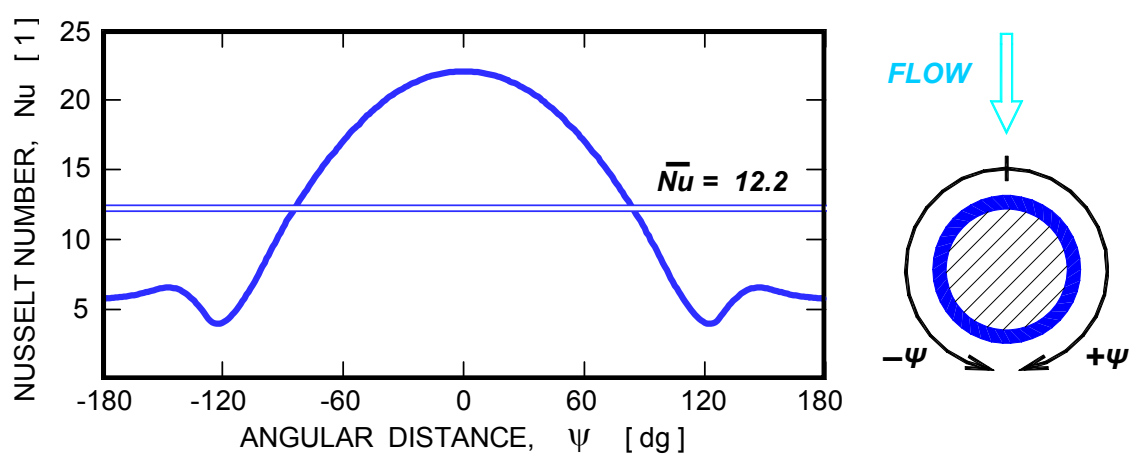

Fig. 4. Distribution of local Nusselt numbers around the circumference of a circular cylinder for cross flow at $R e=597$ (Ref. 3). heat transfer rate from the wire into the surroundings. Local heat transfer is not constant around the wire circumference, as shown in Fig. 4 (Ref. 3). The plot shows the distribution of Nusselt numbers around circumference of a cylinder in cross flow at a Reynolds number of 600. Total heat flux rate, however, depends on the average heat transfer (double line in Fig. 4), which is why a single wire probe is sensitive only to velocity magnitude and not to a velocity direction.

The flow field in the NASA LSAC is predominantly twodimensional in the tangential-axial plane. Probes with two mutually perpendicular wires can be used for simultaneous measurement of two velocity components. However, these probes require complex calibration, and mainly, they are quite fragile for the relatively harsh environment in a compressor test cell. A suitable probe for such measurements must have excellent directional sensitivity. Also probe ruggedness and longevity are very important considerations. On the other hand, the frequency response can be moderate, because the blade passing frequency in the LSAC is only $640 \mathrm{~Hz}$.

A split-fiber probe can satisfy these criteria. References on application of split-fiber probes are relatively rare; only Refs. 4 and 5 are relevant to our case. The split-fiber probe is shown in Fig. 5 (Ref. 6). The probe has two thin films deposited on a quartz cylinder $200 \mu \mathrm{m}$ in diameter. Each film has an active length of $1.25 \mathrm{~mm}$ and covers slightly less than one half of the quartz cylinder circumference. Because the split-fiber probe has its circumference divided into two independent parts, each of these halves averages the partial heat transfer separately, and the average value in each part is now dependent on the velocity direction (probe incidence angle) as shown in Fig. 6. Finally, Fig. 7 shows the distribution of heat transfer rate (Nusselt number) at a Reynolds number of 172 for both halves of the probe as a function of the incidence angle (flow velocity direction relative to probe yaw orientation). As seen here, this dependence is linear at least within the incidence angle range $\pm 40 \mathrm{dg}$. It indicates that the split-fiber probe direction characteristic should be linear at least in the same range of incidence angles.

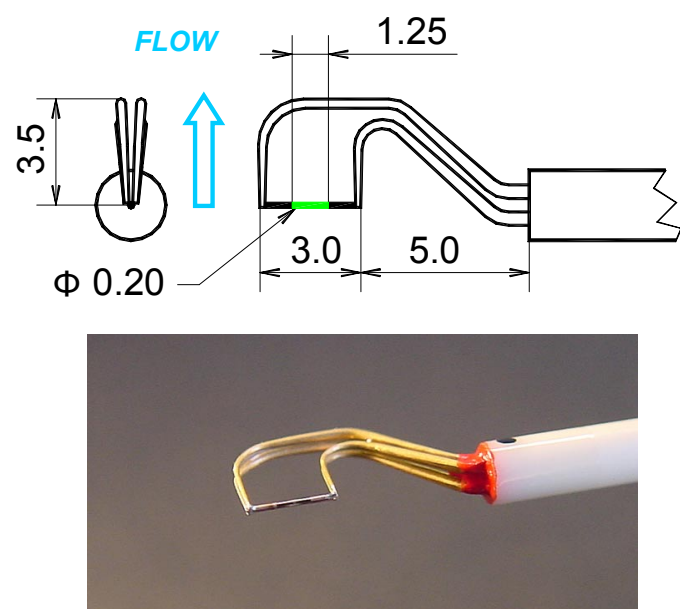

Fig. 5. Split-fiber probe Dantec 55R57 (dimensions in millimeters). 


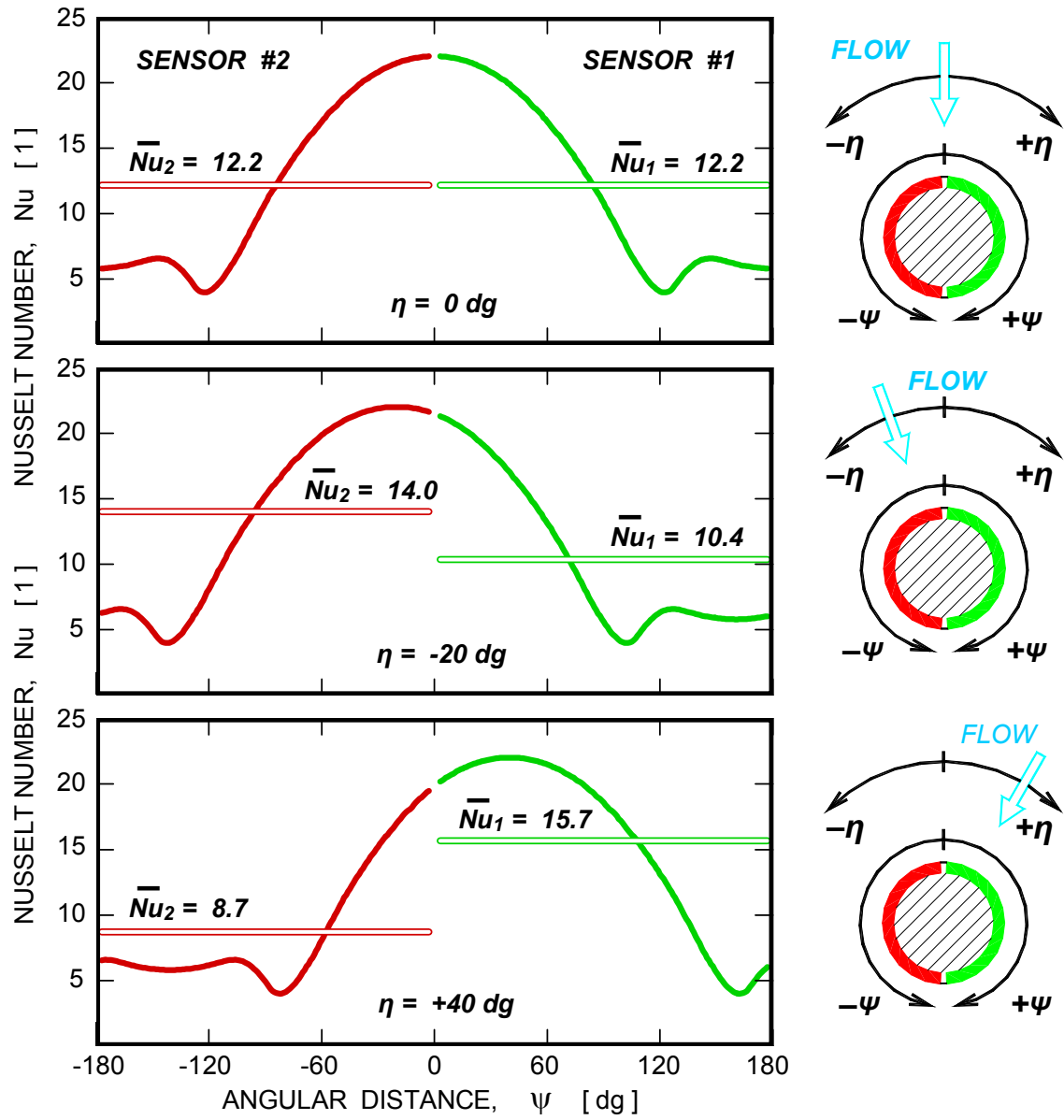

Fig. 6. Distribution of local Nusselt numbers on a split-fiber probe for various flow incidence angles $\eta(R e=597)$.

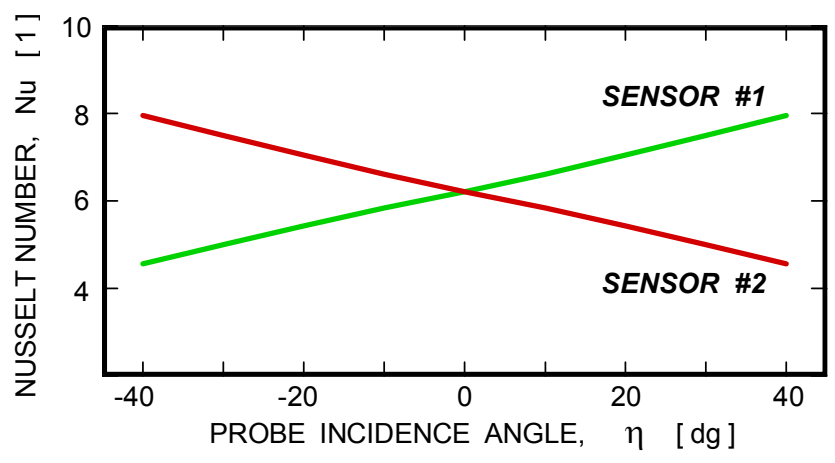

Fig. 7. Distribution of average Nu numbers on a split-fiber probe for various flow incidence angles $(R e=172)$.

\section{SPLIT-FIBER PROBE CALIBRATION}

Probes were calibrated in a free jet flow emanating from a 38.1- $\mathrm{mm}$ round nozzle into ambient surroundings. The sensing element was located at the jet centerline at a distance of $0.9 * D_{J}$ downstream of the nozzle exit plane, it is still well within the jet potential core. The probes were calibrated for the velocity range from $10 \mathrm{~m} / \mathrm{s}$ to $50 \mathrm{~m} / \mathrm{s}$, which corresponds to a range of probe Reynolds numbers from 140 to 700 . Directional sensitivity was calibrated for a range of probe incidence angles from $-35 d g$ to $+35 \mathrm{dg}$ at several flow velocities.

The static pressure at the measurement station in the LSAC is slightly higher than the ambient static pressure at which the probes were calibrated. No corrections were applied to calibration data either for compressibility or molecular effects. First, the compressor pressure ratio is only 1.042 and the maximum local Mach number is 0.12 , so the flow can be considered incompressible. Second, molecular effects should be considered for slip flow conditions only; there is no need for corrections in continuum flow. Flow is considered continuum for Knudsen number less than 0.01 (Ref. 2). The Knudsen number for thermoanemometer probes is defined as the ratio of the mean free path of fluid molecules to a hot-wire or film-cylinder diameter (Ref. 7). For a $200 \mu m$ cylinder and ambient conditions the Knudsen number is about 0.0003 , which is well below the limit. For a conventional hot-wire probe with a wire diameter of $2.5 \mu \mathrm{m}$, the corresponding Knudsen number would be 0.025 and molecular effects would have to be considered.

Velocity calibration curves are shown in Fig. 8. For a symmetric probe at a flow incidence angle of $0 d g$, the calibration curves for both sensors are practically identical. The experimental data points were fitted with a polynomial fit of the fourth order.

The directional characteristics of both sensors for a flow velocity of $49.1 \mathrm{~m} / \mathrm{s} \quad(R e=570)$ are shown in Fig. 9. The characteristics show the predicted trend based on the variation

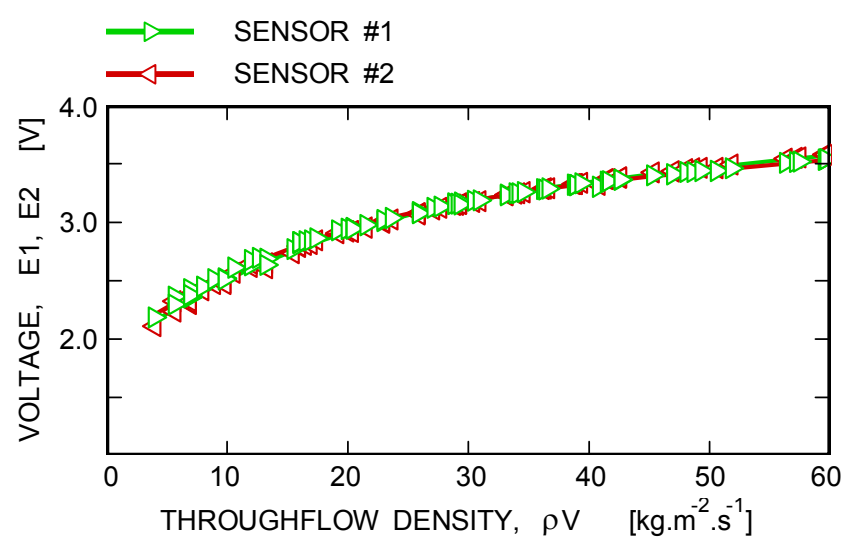

Fig. 8 Velocity calibration a split-fiber probe. 


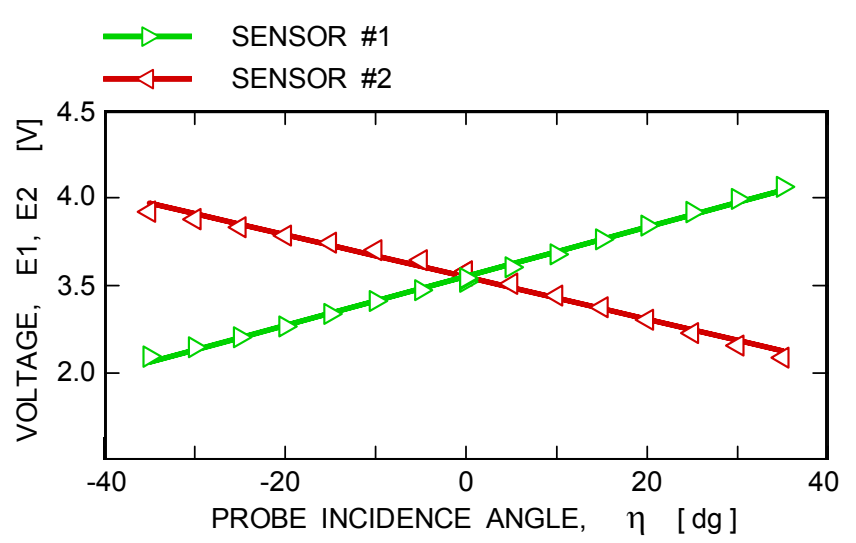

Fig. 9 Direction calibration a split-fiber probe at throughflow density of $58.8 \mathrm{~kg} \cdot \mathrm{m}^{-2} \cdot \mathrm{s}^{-1}(\operatorname{Re}=570)$.

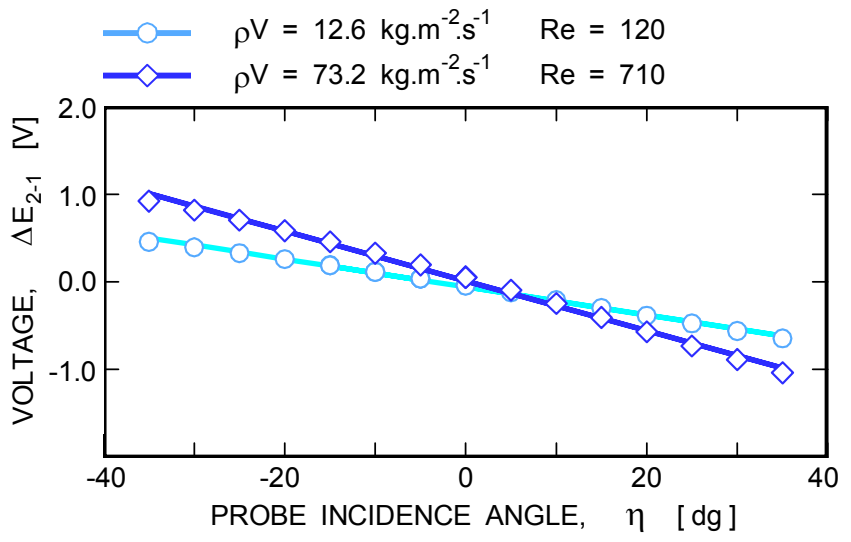

Fig. 10. Differential direction calibration characteristics of a split-fiber probe.

of Nusselt number with the flow incidence (Fig. 7). Data sets for each sensor were fitted with straight lines in the range of incidence angles of $\pm 35 d g$. The fitted line of sensor \#1 has a positive slope, while the line of sensor $\# 2$ has a negative slope. This means that an increase of the flow incidence angle will always increase the voltage of sensor \#1 and simultaneously lower the voltage of sensor \#2 anywhere within the calibrated range. A differential directional characteristic is shown in Fig. 10. It is the difference between the signal voltage of sensor \#2 and the voltage of sensor \#1 plotted as a function of the probe incidence angle. As seen here, the slope of the differential characteristic depends slightly on the probe Reynolds number (e.g. flow velocity in this case). The two data sets in this figure represent the maximum and minimum probe Reynolds number encountered during the experiments in the LSAC. Of course, the effects of Reynolds number on the directional characteristics must be accounted for in the data reduction procedure.

Dynamic calibration (frequency response) was carried out by a square-wave test (Ref. 2). This is an indirect method in which a small electronic square-wave signal is imposed on an anemometer resistor bridge instead of submitting the hot-element probe to flow with sudden velocity perturbations. Observing the response to electronic square waves, the entire anemometer system can be optimized for the best frequency response. The anemometer was optimized at the highest velocity to be measured, $50 \mathrm{~m} / \mathrm{s}$ in our case, because the instabilities in the system usually tend to occur at higher flow velocities. Based on the results of the square-wave test, it was found that the frequency response of the split-fiber probe is flat up to $12 \mathrm{kHz}$. Above this frequency, the probe signal decays. The cut-off frequency of $12 \mathrm{kHz}$ is more than adequate, since the compressor blade passing frequency is only $640 \mathrm{~Hz}$.

\section{DATA REDUCTION PROCEDURE}

A simplified flow chart of data reduction procedure is shown in Fig. 11. The procedure is an iterative process that is repeated for each signal sample from a recorded data set. The iterative procedure consists of four main steps. The inputs in the first step are instantaneous voltages measured from both sensing elements of a split-fiber probe $E 1(t)$ and $E 2(t)$, and a best guess of a throughflow density value $\rho V(\xi=0)$. An initial guess of the throughflow density value is either based on the data from steady state aerodynamic probes or computational predictions. Probe flow incidence angle $\eta(t)$ is then determined from the voltage difference $\Delta E(t)=E 2(t)-E 1(t)$ using the differential direction characteristic that corresponds to the preselected throughflow density $\rho V(\xi)$.

Flow incidence $\eta(t)$ and initial throughflow density $\rho V(\xi)$ are used, in the second step, to determined voltage deviations $\delta E 1(\eta)$ and $\delta E 2(\eta)$, which are differences between a signal voltage at flow incidence $\eta(t)$ and a signal voltage at zero incidence for the same throughflow density $\rho V(\xi)$. Probe directional characteristics are used in this step.

In the third step, the velocity characteristics of both sensors, determined for probe zero incidence angle, are utilized. First, the signal voltages $E 1(t)$ and $E 2(t)$ are corrected for the effect of incidence angle $\eta(t)$ by subtracting the deviations $\delta E 1(\eta)$ and $\delta E 2(\eta)$ respectively, which results in zero incidence voltages $E 1_{0}$ and $E 2_{0}$. Now, throughflow densities for both sensors, $\rho V 1$ and $\rho V 2$, can be determined using velocity characteristics.

Finally, in the last step, the values of throughflow densities, $\rho V 1$ and $\rho V 2$, are compared. If these values are not equal, or the difference is not smaller than a prescribed threshold, then a new value of throughflow density $\rho V(\xi+1)$ is computed as an average of values $\rho V 1$ and $\rho V 2$. The value $\rho V(\xi+1)$ is now the new initial value of throughflow density used in STEP 1 and the entire procedure is repeated again. If both values $\rho V 1$ and $\rho V 2$ are equal or the absolute value of their difference is smaller than a preselected threshold, then the 

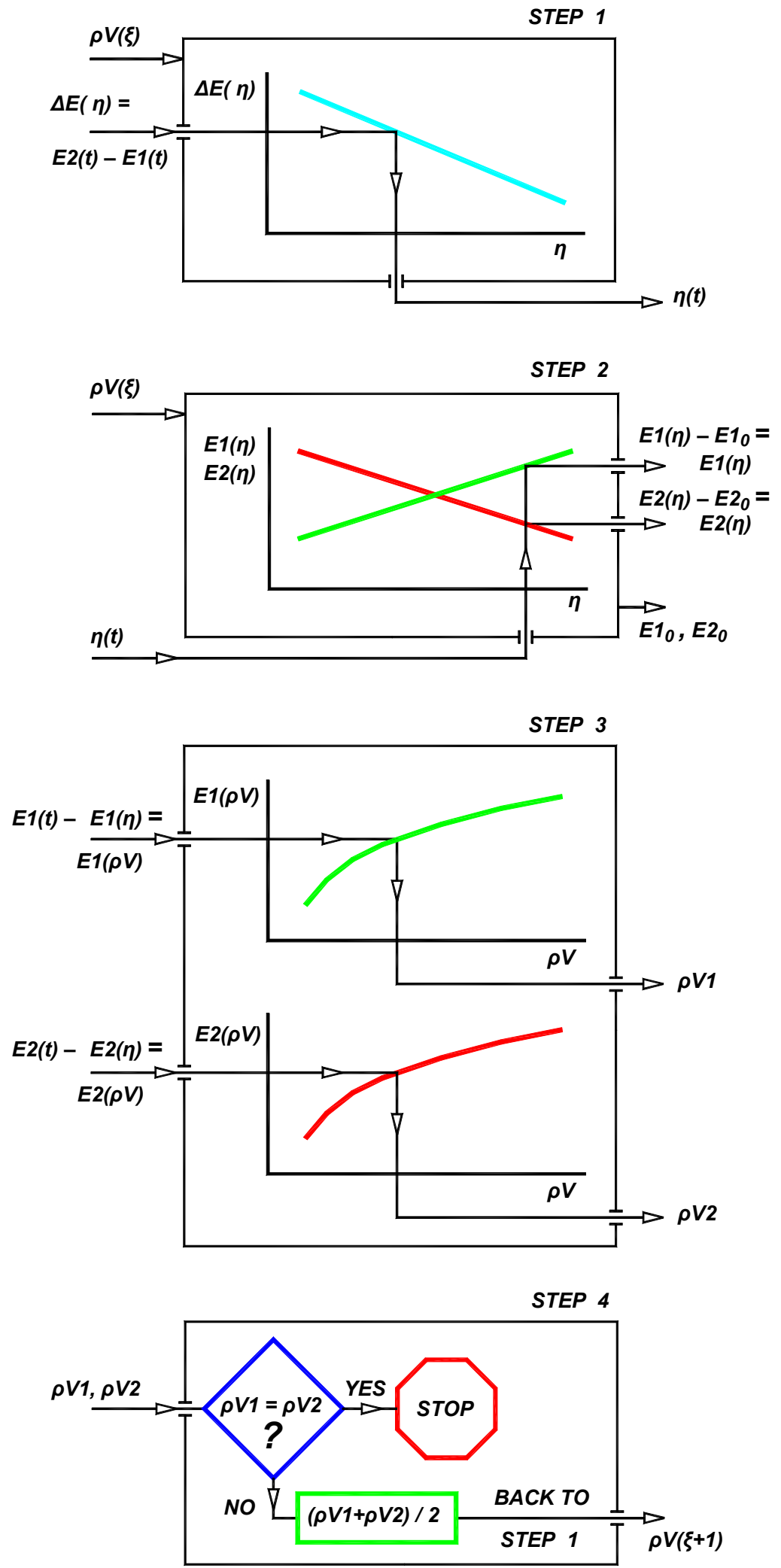

Fig. 11. Flow chart of the data reduction procedure. iterative process is stopped. The resulting flow incidence, for the given data sample acquired at time instant $t$, is $\eta(t)$ and the throughflow density is $\rho V(\xi)$. The data reduction process for time instant $t$ is completed and the procedure marches to the next sample at instant $t+1$, until the entire data set is converted from signal voltages to data sets of probe incidence angle and throughflow density.

The progression of data reduction steps is illustrated in Figs. 12 through 14. Individual diagrams show data segments of $40 \mathrm{~ms}$, which in the time domain corresponds to about $60 \%$ of one rotor revolution. Raw data signals, as recorded by a data acquisition system, are presented in Fig. 12. The first diagram shows a once-perrevolution (OPR) signal. It is an output from an electromagnetic sensor that faces the compressor shaft. The second diagram shows a once-per-blade (OPB) signal. This signal is generated by an optical proximity probe mounted in the compressor shroud at midchord of the first rotor blades. The variations in the pulses generated by passing blades might indicate slight differences in the height of individual blades, but more probably are a consequence of variations in optical reflectivity from blade to blade. The probe was not calibrated for distance measurement, nor were the surfaces of the blade tips treated to achieve uniform reflectivity; the probe merely served as a timing device. Both OPR and OPB signals were utilized for an ensemble averaging procedure to be discussed later. The third and fourth diagrams present split-fiber probe signals; a signal from sensor \#1 is in the third diagram, and a signal from sensor \#2 is in the fourth diagram. These two signals serve as inputs into the data reduction procedure outlined in Fig. 11.

The reduced data sets for the compressor absolute frame, i.e. the frame of the probe, are shown in Fig. 13. The first diagram shows the time history of the probe incidence angle $\eta$, and the second diagram shows the time history of the throughflow density $\rho V$. These are outputs from the data reduction procedure presented in Fig. 11. The third diagram presents the flow absolute angle $\alpha$. This is the flow angle with respect to the compressor stationary frame, while the incidence angle $\eta$ in the first diagram is the flow angle with respect to the probe coordinate system. The difference between these two angles is determined by the probe setting angle $\varepsilon$ relative to the compressor stationary frame (Fig. 3). Absolute flow velocity $V$ is in the fourth diagram. It is the throughflow density divided by mean flow density at the split-fiber measurement station. The mean flow density is calculated from data measured by steady state aerodynamic probes. Finally, the axial and tangential absolute flow velocities $\left(V_{A X}, V_{T G}\right)$ are shown in the fifth 

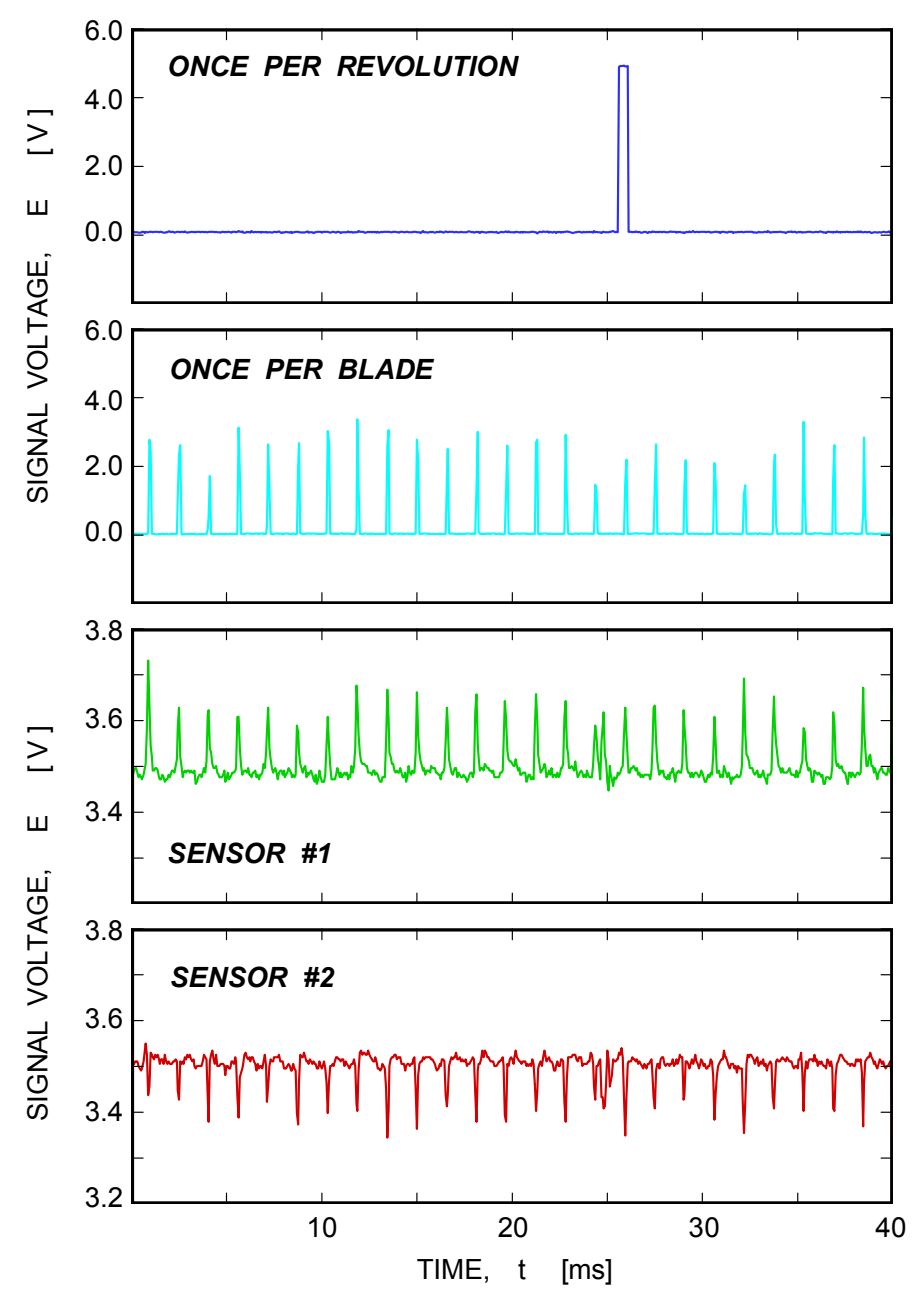

Fig. 12. Raw signals generated by OPR probe, OPB probe, and split-fiber probe.

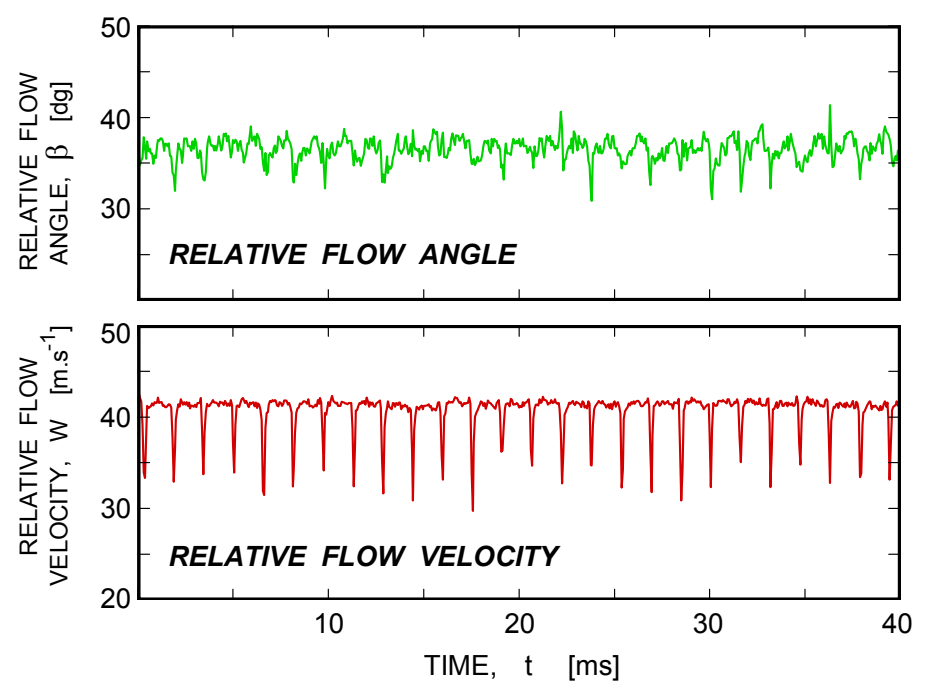

Fig. 14. Flow parameters in the relative flow system.
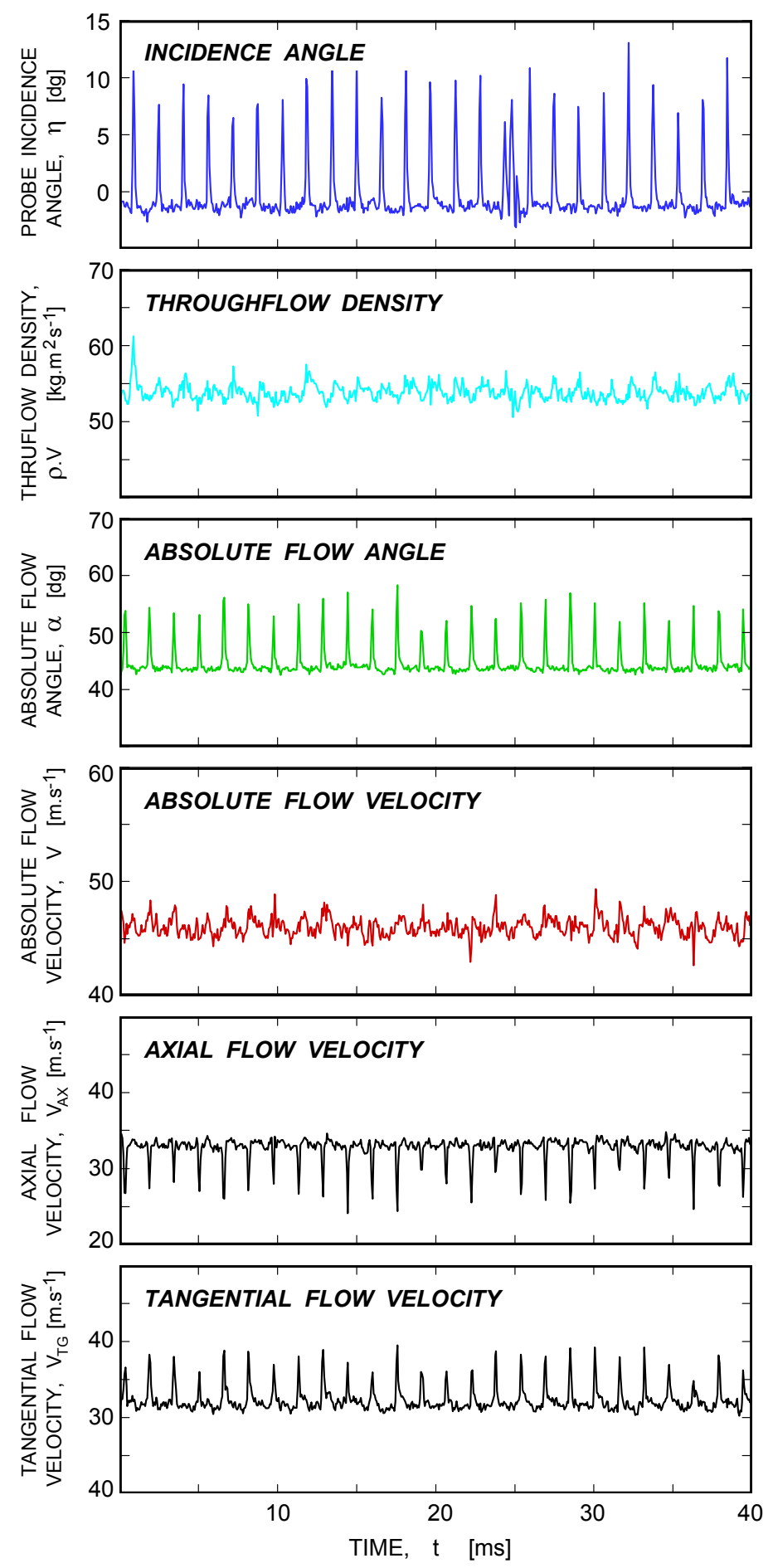

Fig. 13. Flow parameters in the absolute flow system.

and sixth diagrams. Both velocities are vector components of the absolute flow velocity $V$, projected in the respective directions. The axial flow velocity is a parameter in the compressor performance map, while the tangential flow velocity is a measure of energy imparted by the compressor rotor to the flow. 


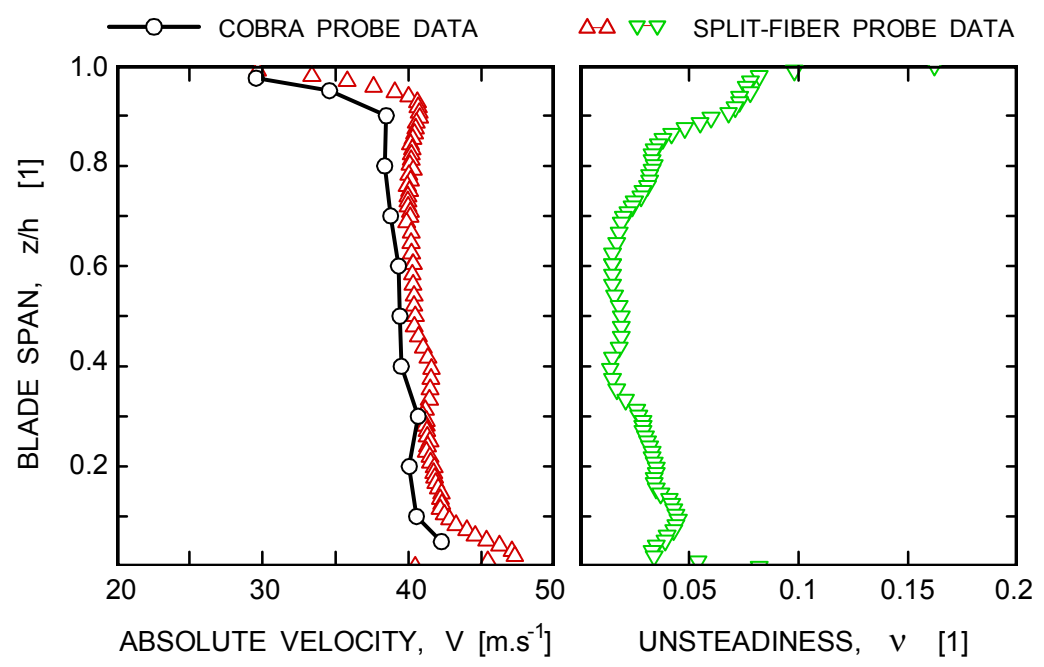

Fig. 15. Absolute flow velocity measured along the blade span by a cobra probe and a split-fiber probe.

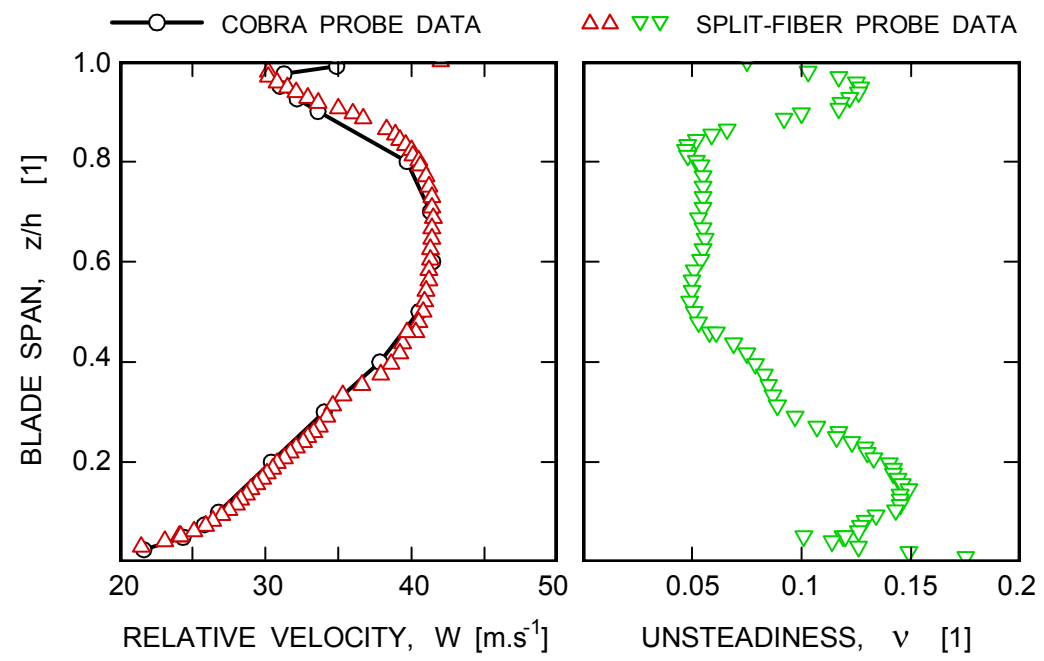

Fig. 16. Relative flow velocity measured along the blade span by a cobra probe and a split-fiber probe.

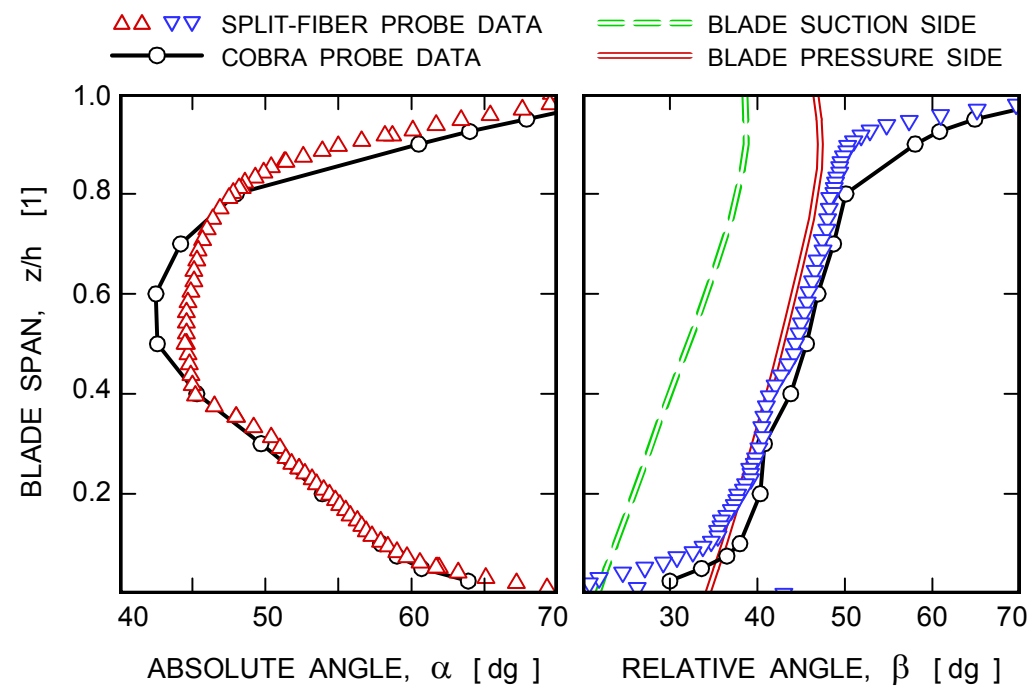

Fig. 17. Absolute and relative flow angles measured by a cobra probe and a split-fiber probe.
Finally, the time histories of relative flow angle $\beta$ and relative flow velocity $W$ are shown in Fig. 14 . These are flow parameters that would be recorded by an observer moving with the revolving rotor. The parameters were determined by vector addition of the absolute flow parameters and the rotational velocity of the compressor rotor. The relative flow velocity is used to determine losses in the compressor rotor.

\section{COMPARISON WITH PNEUMATIC PROBE DATA}

A good test for verifying the reliability of the split-fiber probe data is comparison with mean velocity and flow angle data acquired by pneumatic probes. Such probes have been used for a long time in the LSAC to investigate the mean flow characteristic of this compressor, and the data acquired were verified many times experimentally and computationally. Data selected for comparisons were acquired by three-hole cobra probes following the standard NASA GRC experimental procedures. The cobra probe dimensions are given in Ref. 2. Since the split-fiber probe produces instantaneous data consisting of half a million data samples acquired with a sampling frequency of $80 \mathrm{kHz}$ over an interval of $6.25 \mathrm{~s}$, equivalents of mean data were generated by arithmetic averaging of the instantaneous data over the entire data collection interval. The results are presented in Figs. 15 through 17.

A comparison of absolute velocity data is in the left-hand diagram in Fig. 15. The data were acquired in the first stage of the LSAC along the blade span in the gap between the rotor and the stator. The measurement station is indicated in Fig. 2 by a broken line. As seen in Fig. 15, the velocity measured by the split-fiber probe is about 3 to $4 \%$ higher along the entire span than the cobra probe velocity. It is believed, at present, that the difference is partially due to circumferential nonuniformity of the flow just upstream of the vanes of the first stage stator. The split-fiber probe data were generated at a single circumferential location, while the cobra probe data represent an average of sweeps along the blade height acquired at 41 circumferential locations, which stretches over several stator vane passages. This is a typical procedure used to eliminate the effects of a circumferential nonuniformity of the flow. In general, the comparison between these two sets of data is good. Information about velocity unsteadiness is in the right-hand diagram in Fig. 15. Basically, it is a distribution of standard deviations of instantaneous velocities normalized by local mean velocities. Turbulence intensity is defined identically, however, it involves only random velocity fluctuations. In our case, the unsteadiness represents both random velocity 
fluctuations and also periodic velocity fluctuations. There are three major sources of periodic velocity fluctuations: rotor wakes, blade tip vortices, and the passage corner vortices at the blade root. An increased velocity unsteadiness in the blade tip and root regions can be detected in the data. Of course, this information cannot be furnished by pneumatic probes.

A comparison of relative flow velocity is presented in Fig. 16. The overall agreement is excellent. It seems that there is a small difference in data between the two probes at about $90 \%$ of the blade span, however, the pneumatic data are too sparse in that region to make any definite conclusion. Also the difference is in the region of high velocity

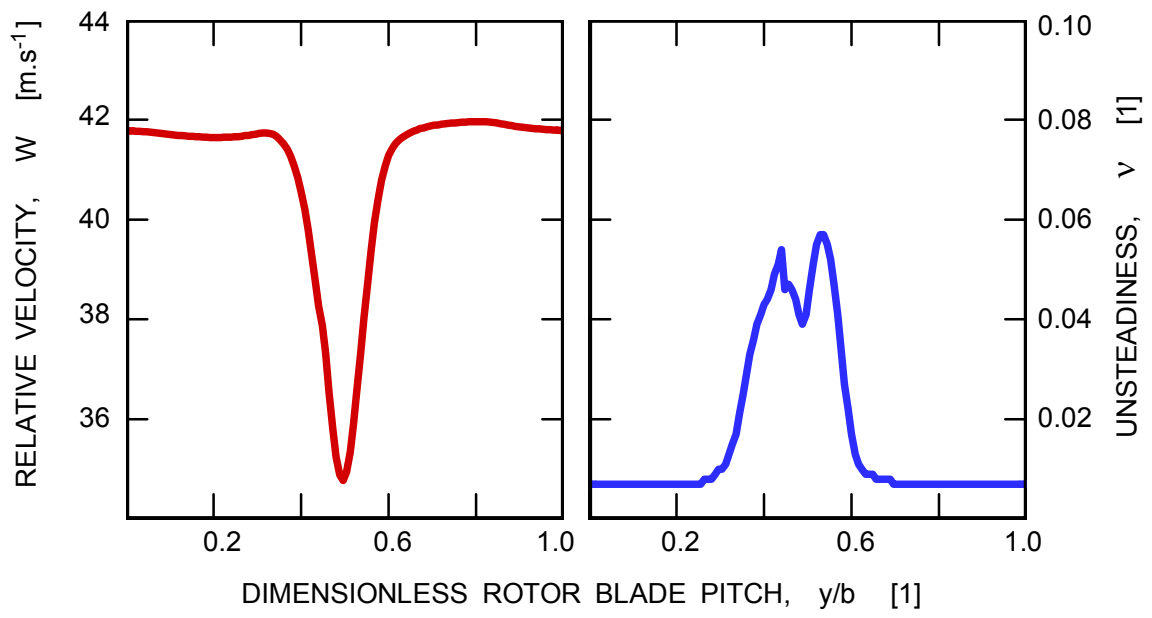

Fig. 18. Distribution of relative flow velocity along a rotor blade pitch at a span height of $z / h=0.604$. unsteadiness; the uncertainty in pneumatic probe data usually increases in flows with high velocity unsteadiness. The cobra probe used is much larger than the split-fiber probe. The cobra probe head is $1.5 \mathrm{~mm}$ wide, while the diameter of the split-fiber probe is only $0.2 \mathrm{~mm}$. Velocity unsteadiness of the relative flow is visibly higher than was the case for the absolute flow, with local peaks at the blade tip and root, which is the consequence of a vortex structure in the flow.

Finally, flow angles are compared in Fig. 17. The absolute flow angles are in the left-hand diagram, and the relative angles are in the right-hand one. Blade 'metal' angles for the suction and pressure sides at the rotor blade trailing edge are also shown in the diagram of relative flow angles. As seen in Fig. 17, the flow angles exhibit regions of differences. Surprisingly, the disagreement of absolute flow angles is in the midspan of the blade, in the region of rather low velocity unsteadiness. The reasons for this disagreement are not understood at present. Relative flow angles, on the other hand, disagree in the tip and root regions of the blade, where it might be expected for the reasons discussed above.

\section{ENSEMBLE AVERAGING AND FREQUENCY ANALYSIS}

An overall very good agreement between the averaged data acquired by a split-fiber probe and a pneumatic probe boosts confidence in the reliability of the unsteady content of the splitfiber probe data. To investigate the features of unsteady data, two methods were used: ensemble averaging and frequency analysis.

Ensemble averaging reduces the random velocity fluctuations, but preserves the periodic content of the velocity signal that is locked to the basis of averaging, which is either the blade passing frequency or the rotor shaft frequency. An example of ensemble averaging based on the blade passing frequency is given in Fig. 18. It shows distributions of relative velocity and velocity unsteadiness over an average rotor blade

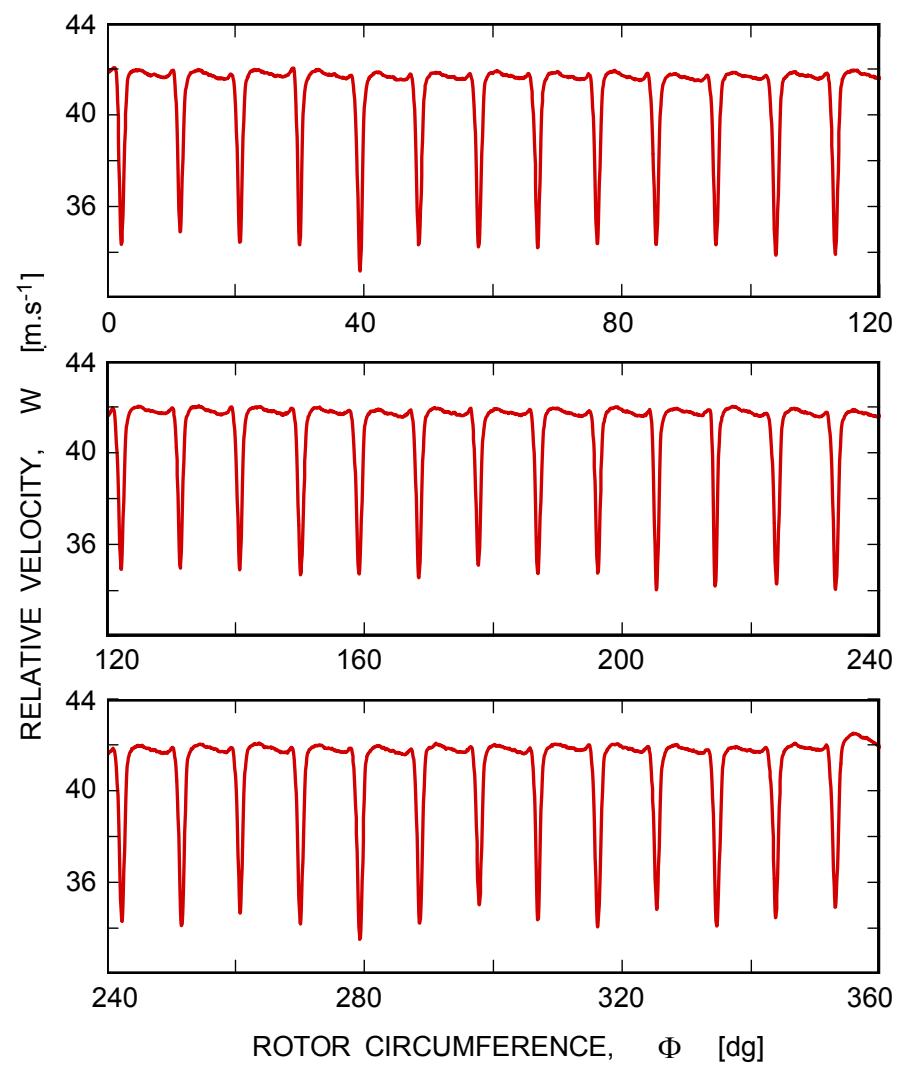

Fig. 19. Relative flow velocity averaged over a rotor circumference at a span height of $z / h=0.604$.

passage (from a midpitch of one blade channel to a midpitch of an adjacent one) at $60 \%$ of blade span. The shape of the wake that is shed from a rotor blade is clearly defined here, showing a $17 \%$ velocity drop in the middle of the wake relative to the midchannel flow. Information like this is crucial to determining losses in a spinning rotor. Velocity unsteadiness exhibits two local peaks that correspond to positions of peak shear stresses in the blade wake. Ensemble averaging based on the blade passing frequency suppresses changes among 
individual rotor blade channels; these changes can be revealed by doing ensemble averaging based on the compressor shaft frequency (once per rotor revolution). An example of rotor based ensemble averaging is in Fig. 19 where the differences among individual rotor blade channels are clearly traceable.

The results of spectral analysis using the digital Fourier transform procedure are shown in Fig. 20. The data set is for the absolute velocity acquired at $89 \%$ of the rotor blade span.

The amplitude spectra were calculated for the entire data set of $6.25 \mathrm{~s}$. The spectral amplitude values are not corrected for frequency leakage. The upper diagram in Fig. 20 shows the overall view of the spectra. The blade passing frequency of $640 \mathrm{~Hz}$ is the most dominant velocity fluctuation (BPF_1h). The second strongest velocity fluctuations occur at a frequency of $16.4 \mathrm{~Hz}$ (SHF_1h), which is the compressor shaft frequency. A second harmonic of the blade passing frequency (BPF_2h) can be also detected here. The middle diagram shows the same spectra, however with a magnified velocity amplitude scale. Multiple shaft frequency harmonics can be seen here. Notice that the blade passing frequency (BPF_1h) is also the 39th harmonic of the compressor shaft frequency (the rotor has 39 blades). Finally, the lower diagram depicts a magnified portion of this spectrum in the vicinity of the blade passing frequency.

Periodic fluctuations in the absolute velocity constitute the major excitation force that is responsible for high cycle fatigue problems of stationary components in turbomachines. All compressor components that are exposed to the fluctuating flow must be tuned for natural frequencies that are far, in the frequency domain, from the most dominant flow fluctuations to minimize the damage due to high cycle fatigue.

\section{SUMMARY OF FINDINGS}

The following experience was gained during the course of this study in which a split-fiber probe was extensively used for unsteady velocity measurements in the NASA LSAC.

- The probe worked reliably during a several months long test program.

- The velocity and directional characteristics of the probe showed only minute changes during the entire test program.

- The probe directional characteristic is linear in the range of flow incidence angles of $\pm 35 d g$.

- An algorithm was developed to decompose the probe signals into velocity magnitude and velocity direction.
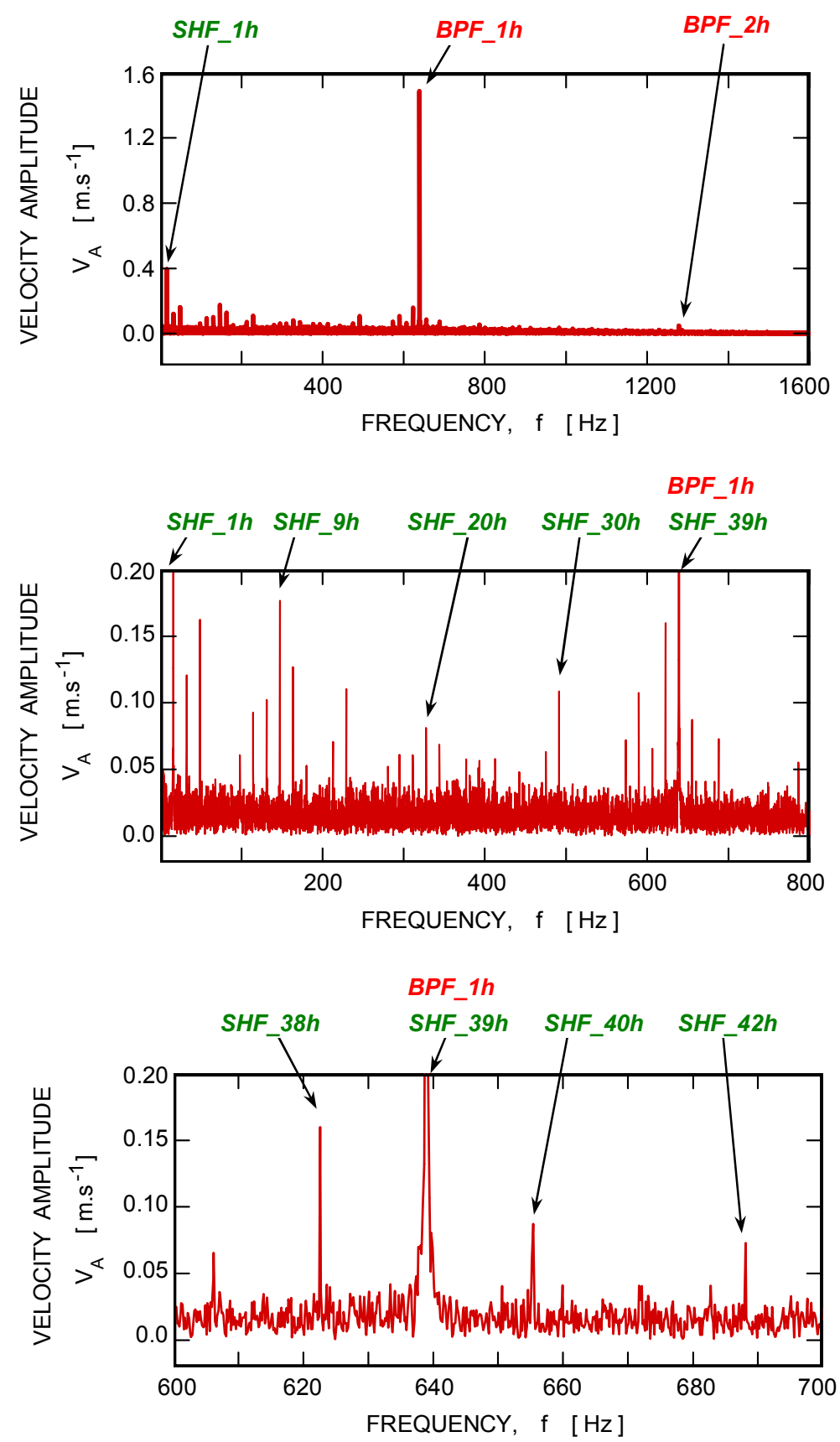

Fig. 20. Frequency analysis of the absolute velocity signal at a span height of $z / h=0.890$.

- Averaged unsteady data agree very well with data acquired by pneumatic probes.

- Velocity distribution in a rotor blade passage was retrieved using the ensemble averaging method.

- Frequencies of excitation forces that may contribute to high cycle fatigue problems were identified by applying a digital Fourier transform to absolute velocity data. 


\section{REFERENCES}

1. Wasserbauer C.A., Weaver, H.F., and Senyitko, R.G.: "NASA Low-Speed Axial Compressor for Fundamental Research", NASA TM-4635, 1995.

2. Bruun, H.H.: "Hot-Wire Anemometry, Principles and Signal Analysis', Oxford University Press Inc., New York, 1995.

3. Eckert, E.R.G. and Soehngen, E.: "Distribution of HeatTransfer Coefficients Around Circular Cylinder in Crossflow at Reynolds Numbers From 20 to 500", Transaction of ASME, Vol. 74, pp.343-347, 1952.

4. Richter, H.: "Measurement of Two-Dimensional Periodic Flow Behind Turbine Guide-Vanes by Means of a SplitFiber Probe”, Dantec Information, no.1, pp.10-12, 1985.

5. Helle, L.: "The use of a split-fiber probe for aerodynamic research", Dantec Information, no.12, pp.17-20, 1993.

6. Dantec Probe Catalog, Publ. No. 2201E, Dantec Electronics Inc., 1982.

7. Norman, B. "Hot-wire Anemometer Calibration at high Subsonic Speeds", DISA Information, No.5, pp.5-19, 1967. 
Public reporting burden for this collection of information is estimated to average 1 hour per response, including the time for reviewing instructions, searching existing data sources, gathering and maintaining the data needed, and completing and reviewing the collection of information. Send comments regarding this burden estimate or any other aspect of this collection of information, including suggestions for reducing this burden, to Washington Headquarters Services, Directorate for Information Operations and Reports, 1215 Jefferson Davis Highway, Suite 1204, Arlington, VA 22202-4302, and to the Office of Management and Budget, Paperwork Reduction Project (0704-0188), Washington, DC 20503.

\begin{tabular}{|l|l|l|}
\hline 1. AGENCY USE ONLY (Leave blank) & $\begin{array}{c}\text { 2. REPORT DATE } \\
\text { June } 2003\end{array}$ & $\begin{array}{c}\text { 3. REPORT TYPE AND DATES COVERED } \\
\text { Final Contractor Report }\end{array}$ \\
\hline
\end{tabular}

4. TITLE AND SUBTITLE 5. FUNDING NUMBERS

Application of a Split-Fiber Probe to Velocity Measurement in the NASA Research Compressor

\section{AUTHOR(S)}

Jan Lepicovsky

WBS-22-708-28-03

NAS3-00145

7. PERFORMING ORGANIZATION NAME(S) AND ADDRESS(ES)

8. PERFORMING ORGANIZATION REPORT NUMBER

QSS Group, Inc.

21000 Brookpark Road

E-14034

Cleveland, Ohio 44135

9. SPONSORING/MONITORING AGENCY NAME(S) AND ADDRESS(ES)

National Aeronautics and Space Administration

Washington, DC 20546-0001

10. SPONSORING/MONITORING AGENCY REPORT NUMBER

NASA CR-2003-212489

FEDSM2003-45607

\section{SUPPLEMENTARY NOTES}

Prepared for the 2003 Fluids Engineering Division Summer Meeting cosponsored by the American Society of Mechanical Engineers and the Japan Society of Mechanical Engineers, Honolulu, Hawaii, July 6-10, 2003. Project Manager, Eric R. McFarland, Turbomachinery and Propulsion Systems Division, NASA Glenn Research Center, organization code 5810, 216-433-5915.

12a. DISTRIBUTION/AVAILABILITY STATEMENT 12b. DISTRIBUTION CODE

Unclassified - Unlimited

Subject Categories: 02 and 07

Distribution: Nonstandard

Available electronically at http://gltrs.grc.nasa.gov

This publication is available from the NASA Center for AeroSpace Information, 301-621-0390.

\section{ABSTRACT (Maximum 200 words)}

A split-fiber probe was used to acquire unsteady data in a research compressor. The probe has two thin films deposited on a quartz cylinder $200 \mu \mathrm{m}$ in diameter. A split-fiber probe allows simultaneous measurement of velocity magnitude and direction in a plane that is perpendicular to the sensing cylinder, because it has its circumference divided into two independent parts. Local heat transfer considerations indicated that the probe direction characteristic is linear in the range of flow incidence angles of $\pm 35^{\circ}$. Calibration tests confirmed this assumption. Of course, the velocity characteristic is nonlinear as is typical in thermal anemometry. The probe was used extensively in the NASA GRC low-speed, multistage axial compressor, and worked reliably during a test program of several months duration. The velocity and direction characteristics of the probe showed only minute changes during the entire test program. An algorithm was developed to decompose the probe signals into velocity magnitude and velocity direction. The averaged unsteady data were compared with data acquired by pneumatic probes. An overall excellent agreement between the averaged data acquired by a split-fiber probe and a pneumatic probe boosts confidence in the reliability of the unsteady content of the split-fiber probe data. To investigate the features of unsteady data, two methods were used: ensemble averaging and frequency analysis. The velocity distribution in a rotor blade passage was retrieved using the ensemble averaging method. Frequencies of excitation forces that may contribute to high cycle fatigue problems were identified by applying a fast Fourier transform to the absolute velocity data.

\section{SUBJECT TERMS}

Thermoanemometry; Unsteady flow velocity; Axial compressor

\begin{tabular}{|c|c|c|}
\hline $\begin{array}{c}\text { 17. SECURITY CLASSIFICATION } \\
\text { OF REPORT }\end{array}$ & $\begin{array}{c}\text { 18. SECURITY CLASSIFICATION } \\
\text { OF THIS PAGE } \\
\text { Unclassified }\end{array}$ & $\begin{array}{c}\text { 19. SECURITY CLASSIFICATION } \\
\text { OF ABSTRACT } \\
\text { Unclassified }\end{array}$ \\
\hline
\end{tabular}

